\title{
Meta-analysis on insulin treatment for type 2 diabetes: rushed conclusions?
}

\author{
A. M. Wägner • D. Mauricio
}

Received: 5 November 2009 / Accepted: 23 December 2009/Published online: 17 February 2010

(C) Springer-Verlag 2010

Keywords Glycaemic control $\cdot \mathrm{HbA}_{1 \mathrm{c}} \cdot$ Hypoglycaemia . Insulin therapy $\cdot$ Intention to treat $\cdot$ Randomised clinical trials · Titration

\section{Abbreviation \\ 4-T Treating to Target in Type 2 Diabetes}

To the Editor: We read the meta-analysis by Lasserson et al. [1], published in Diabetologia, with interest. However, there are several issues relevant to the conclusions of this paper that are worth pointing out.

Most of the conclusions are based on five studies for the comparison of basal vs biphasic insulin, seven studies for the comparison of prandial vs basal (two of which were included in the previous comparison) and three for the comparison of prandial vs biphasic; certainly not the 22

\section{A. M. Wägner $(\bowtie)$}

Department of Endocrinology and Nutrition,

Complejo Hospitalario Universitario Insular Materno-Infantil,

Av. Marítima del sur s/n,

Las Palmas de Gran Canaria 35016, Spain

e-mail: awagfah@gobiernodecanarias.org

\section{A. M. Wägner}

Department of Medical and Surgical Science,

Universidad de Las Palmas de Gran Canaria,

Gran Canaria, Spain

D. Mauricio

Department of Endocrinology and Nutrition,

Hospital Universitari Arnau de Vilanova,

Lleida, Spain

D. Mauricio

Institut de Recerca Biomèdica de Lleida,

Lleida, Spain randomised clinical trials and more than 4,000 participants described in the abstract and methods section. This may be somewhat misleading to readers.

The quality of the studies included in the meta-analysis was low. Given the fact that none was blinded, the maximum expected score for these studies would be four (three out of the five Jadad points [2], plus one for intention-to-treat analysis), but the authors give five points to two of these studies.

Two of the authors (R. R. Holman and A. J. Farmer) are also co-authors of the largest study (Treating to Target Type 2 Diabetes [4-T]) [3] included in the metaanalysis, and longer follow-up results of this study [4] have recently been published that are quite different from those given by Lasserson et al. [1]. Indeed, given the weight of the 4-T study in the meta-analysis, if the 3 year results were to be included, the superiority of the other two patterns of insulin administration relative to basal insulin would probably disappear.

The insulin doses used in the basal regimen were consistently lower in the studies reporting this information. Little emphasis is given to this fact in the discussion, even though it is probable that under-titration of basal insulin plays a role in the results obtained. Indeed, this is something that has been pointed out previously for the 1 year results of the 4-T study [5].

All basal insulins are included in the same analysis, despite the fact that higher doses of insulin detemir [B29Lys ( $\varepsilon$-tetradecanoyl),desB30 human insulin] than NPH insulin [6] or insulin glargine (A21Gly,B31Arg,B32Arg human insulin) [7] are needed to obtain equivalent effects.

Finally, type 2 diabetes is characterised by the progressive loss of insulin secretion. Thus, the time-point in the development of the disease is an aspect to be taken into 
consideration when choosing the optimal therapy for each patient. Basal insulin administration would be chosen for individuals with a high level of fasting glycaemia, whereas regimens based on quick-acting insulins would be expected to cover prandial hyperglycaemia. Furthermore, individual patient features, titration and meal distribution are central for achievement of glycaemic optimisation and for avoidance of hypoglycaemia. Individual features have to be taken into consideration in any treatment, but a tailored algorithm is especially important in the context of insulin administration.

Acknowledgements A. M. Wägner is being supported by grants from the European Foundation for the Study of Diabetes (EFSD)/ Novo Nordisk/JDRF 2008 Programme for Type 1 Diabetes, Instituto de Salud Carlos III (PI08/1113) and Fundación Canaria de Investigación y Salud (FUNCIS-PI 16/07), and D. Mauricio, from Instituto de Salud Carlos III (PI 061104)

Duality of interest A. M. Wägner has received support from Novo Nordisk, Eli Lilly and sanofi-aventis for participation in scientific meetings. D. Mauricio has received speaker's fees or has participated in Advisory Board activities for Eli Lilly and sanofi-aventis. The authors are not aware of any other conflicts of interest related to the contents of the manuscript.

\section{References}

1. Lasserson DS, Glasziou P, Perera R, Holman RR, Farmer AJ (2009) Optimal insulin regimens in type 2 diabetes mellitus: systematic review and meta-analyses. Diabetologia 52:19902000

2. Jadad AR, Moore RA, Carroll D, Jenkinson C, Reynolds DJM, Gavaghan DJ, McQuay HJ (1996) Assessing the quality of reports of randomized clinical trials: is blinding necessary? Control Clin Trials 17:1-12

3. Holman RR, Thorne KI, Farmer AJ, et al, for the 4-T Study Group (2007) Addition of biphasic, prandial, or basal insulin to oral therapy in type 2 diabetes. N Engl J Med 357:1716-1730

4. Holman RR, Farmer AJ, Davies MJ, et al, for the 4-T Study Group (2009) Three-year efficacy of complex insulin regimens in type 2 diabetes. N Engl J Med 361:1736-1747

5. Dagdelen S (2008) Addition of insulin to oral agents in type 2 diabetes. N Engl J Med 358:1197

6. Brunner GA, Sendhofer G, Wutte A et al (2000) Pharmacokinetic and pharmacodynamic properties of long-acting insulin analogue NN304 in comparison to NPH insulin in humans. Exp Clin Endocrinol Diabetes 108:100-105

7. Rosenstock J, Davies M, Home PD, Larsen J, Koenen C, Schernthaner G (2008) A randomised, 52-week, treat-to-target trial comparing insulin detemir with insulin glargine when administered as add-on to glucose-lowering drugs in insulin-naive people with type 2 diabetes. Diabetologia 51:408-416 